\title{
The gap between clinical gaze and systematic assessment of movement disorders after stroke
}

\author{
Hanneke JM van der Krogt ${ }^{1 *}$, Carel GM Meskers ${ }^{1 *}$, Jurriaan H de Groot ${ }^{1}$, Asbjørn Klomp ${ }^{1,2}$ and J Hans Arendzen ${ }^{1}$
}

\begin{abstract}
Background: Movement disorders after stroke are still captured by clinical gaze and translated to ordinal scores of low resolution. There is a clear need for objective quantification, with outcome measures related to pathophysiological background. Neural and non-neural contributors to joint behavior should be separated using different measurement conditions (tasks) and standardized input signals (force, position and velocity).

Methods: We reviewed recent literature for the application of biomechanical and/or elektromyographical (EMG) outcome measures under various measurement conditions in clinical research.

Results: Since 2005, 36 articles described the use of biomechanical and/or EMG outcome measures to quantify post-stroke movement disorder. Nineteen of the articles strived to separate neural and non-neural components. Only 6 of the articles measured biomechanical and EMG outcome measures simultaneously, while applying active and passive tasks and multiple velocities.

Conclusion: The distinction between neural and non-neural components to separately assess paresis, stiffness and muscle overactivity is not commonplace yet, while a large gap is to be bridged to attain reproducible and comparable results. Pathophysiologically clear concepts, substantiated with a comprehensive and concise measuring protocol will help professionals to identify and treat limiting factors in movement capabilities of poststroke patients.
\end{abstract}

Keywords: Stroke, Biomechanics, Electromyography, Outcome measures

\section{Review} Introduction

Movement disorders after stroke are the result of a complex interaction of primary neural damage and secondary tendomuscular changes $[1,2]$. The combination of paresis, stiffness and muscle overactivity leads to a phenotype that is easy to recognize clinically, but hard to quantify [1]. The broadly used term "spasticity" is under debate. Different definitions are used, and while it is mostly used as an umbrella-term for the phenotype, it describes only a part of the movement disorder [3-7], and has little relation to the capabilities of a patient to perform under different circumstances.

Clinical gaze and manual tests to assess movement disorder after stroke are readily available to every physician and are currently used as a basis for clinical

\footnotetext{
* Correspondence: j.m.van_der_krogt@lumc.nl; c.g.m.meskers@lumc.nl 'Department of Rehabilitation Medicine, Leiden University Medical Centre, Leiden, Netherlands

Full list of author information is available at the end of the article
}

practice. However, there are some difficulties in evaluating interventions within patients and between studies. For example, resolution of clinical tests is low, rater dependency is variable and conditions are difficult to standardize [8,9]. Little is known about responsiveness of the clinical tests to change. Ordinal scales are often misused as linear entities. Also, the measured construct of tests is not always taken into account when choosing a test for the assessment of stroke patients [9], i.e. improvement in tests on the domains of body structures and functions of the International Classification of Functioning, Disability and Health (ICF) do not automatically lead to improvement in the domains of activities and participation.

Correct use of a meaningful pathophysiological construct will enable clinicians to target their expensive and labor intensive therapies such as botulinum toxin and exercise programs more efficiently and effectively. Evidently, this challenges the community of rehabilitation specialists to quantify and objectify the components of

\section{Biomed Central}


movement disorders according to their pathophysiological origin $[10,11]$ and their relevance for performance in the different ICF domains. For the domain of Body Structures and Body Functions this means that, first of all, input signals (e.g. velocity, force, angle) should be standardized to enable comparability and repeatability. Second, multiple measuring conditions should be applied to trigger the different pathophysiological components $[10,11]$, i.e. active tasks to study voluntary muscle properties, passive tasks to study passive tissue properties, and multiple measurement velocities to elicit stretch reflexive behavior. This will allow for differentiation in neural and non-neural components (see Table 1), and will enable clinicians to direct their therapies more precisely. Simultaneously used biomechanical and electrophysiological techniques can support the identification of active, passive and reflexive components and their complex (non linear) interactions.

Recommendations for objective and quantitative assessment of movement disorders after stroke are readily available $[6,9,12,13]$. However, it is unclear to which extent these recommendations are implemented in current research and clinical practice. The aim of the present paper is to provide an overview of biomechanical and electrophysiological outcome measures recently used to describe post-stroke movement disorders. In addition, the use of underlying pathophysiological constructs is investigated.

\section{Methods}

We conducted a literature search on PubMed and Web of Science with the following search terms: PubMed: stroke AND biomechanics AND electromyography (limits: last 5 year, human, adult)(accessed dec 2010). Web of Science: TS $=(($ stroke AND outcome measures $)$ AND (biomechanic OR electromyography)). We also tracked references and citations. Thereafter we checked for doubles and scanned titles and abstracts. For a flow chart of the search, see Figure 1.

Within the found references, we identified biomechanical and electromyographical (EMG) outcome measures, used in research on stroke patients. We searched for the

Table 1 Division of components of post stroke movement disorder in non-neural and neural properties offers a construct for targeted therapy: an overview

\begin{tabular}{lll}
\hline & $\begin{array}{l}\text { Measuring } \\
\text { condition }\end{array}$ & Construct \\
\hline Non-neural & Passive & $\begin{array}{l}\text { Stiffness, changed properties } \\
\text { of connective tissue and joints }\end{array}$ \\
\hline Neural & Active & $\begin{array}{l}\text { Paresis, diminished voluntary } \\
\text { muscular capacity }\end{array}$ \\
\hline & Reflexive & Muscle overactivity, stretch \\
& (velocities) & reflex behavior \\
\hline
\end{tabular}

pathophysiological construct of these outcome measures, given by the authors. Biomechanical and EMG outcome measures were examined for task instruction (active or passive) and for applied velocities of perturbations (slow, fast or multiple velocities). Subsequently, the outcome measures were separated in clusters, according to the applied method. For biomechanical outcome measures, the clusters were: range of motion, stiffness (or resistance to passive movement), maximum voluntary contraction, viscosity, work, mathematical models, other. For EMG outcome measures, the clusters were: magnitude, threshold (angle), onset (time), co-activation, other.

\section{Results}

The search yielded 37 articles. A flowchart of the search is illustrated in Figure 1. Study characteristics (measured segment, number of subjects, category of research) and the biomechanical and electrophysiological outcome measures found in each article, are summarized in Additional file 1: Table S1.

Of the 37 articles, 3 were review articles [14-16]. In the other 34 articles, 30 included EMG outcome measures [17-45] and 31 included biomechanical outcome measures, while 25 articles included both. Active and passive tasks were found in 10 articles $[17,19,20,26,27,29,33,34,38,46]$. Different measuring velocities were found in 19 articles [18-22,24,27,30-35,37$39,43,44,47]$. In 6 articles, all of the aforementioned properties were present (see Figure 2) [19,20,27,33,34,38].

In 6 articles the biomechanical and/or EMG were used to evaluate treatment of stroke patients $[17,26,28,31,37,43]$, 10 articles addressed reliability or feasibility of the outcome measures in stroke patients [20,21,23,32,35,44,45,47-49] and 18 articles were observational (difference between healthy subjects and stroke patients) or tested a new measuring method $[18,19,22,24,25,27,29,30,33,34,36,38$ $42,46,50]$. A total of 682 stroke patients and 175 healthy subjects were included (see Additional file 1: Table S1).

In 25 articles the biomechanical and EMG techniques were used to objectify or quantify a clinical concept (e.g. spasticity, muscle tone, muscle activity, impairment or coupling) $[18,20,22-27,29-33,35,37,39-47,50]$. Alongside this, a large part of the articles use these techniques to separate the underlying (neural and non-neural) mechanisms of the concept $(n=19)$ [18-24,30,31,33$35,37,39,40,42-45]$. Finally, there is also a small number of articles that advocate standardized input $(n=6)$ [19$21,24,30,40]$.

\section{Biomechanical outcome measures}

An overview of biomechanical outcome measures is presented in Additional file 1: Table S1. 


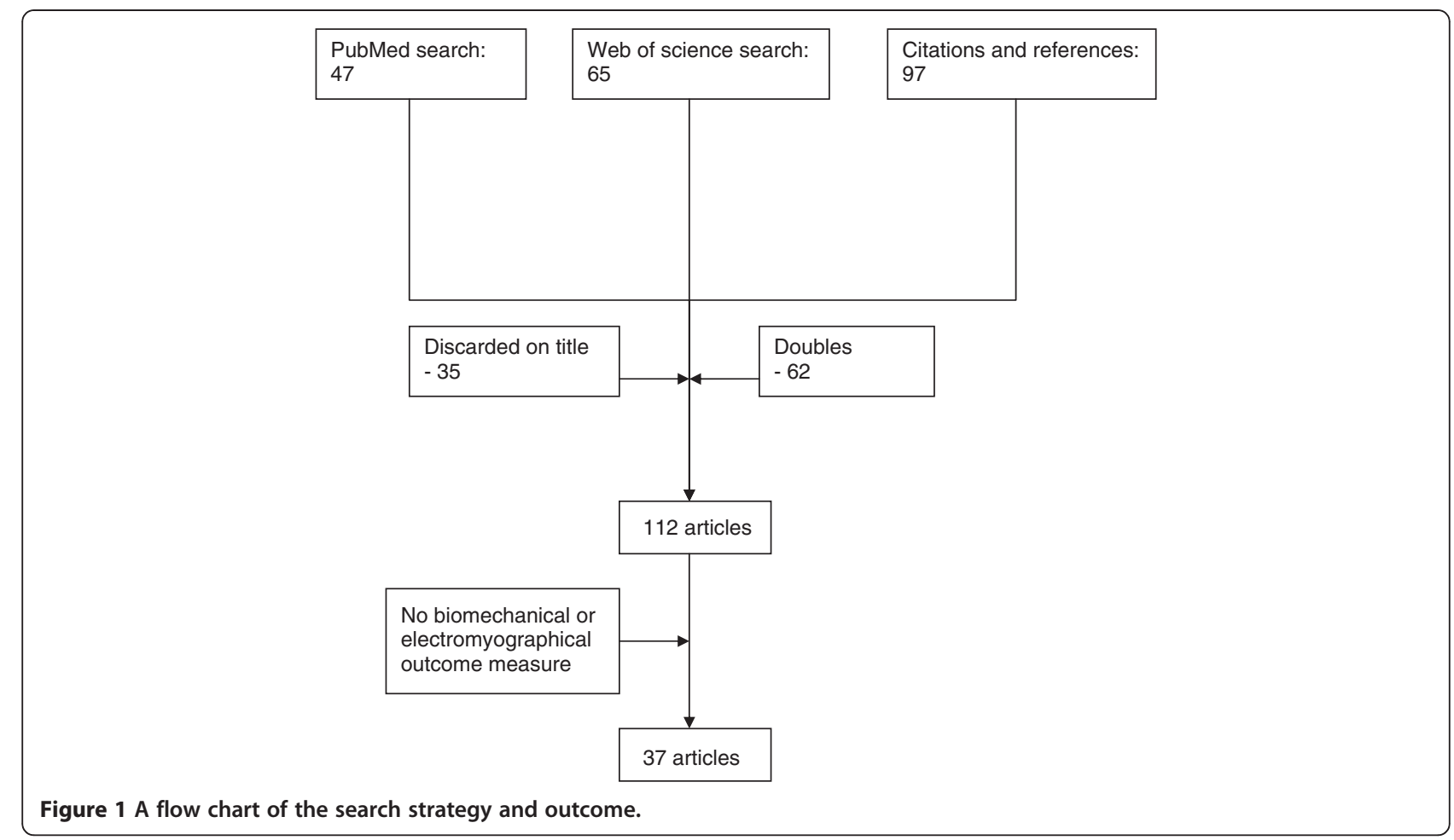

Range of motion was assessed as passive range of motion (pain-free or comfortable range of movement about a joint) $(\mathrm{n}=12)$, active range of motion $(\mathrm{n}=3)$ or both $(\mathrm{n}=3)$. An electrogoniometer was used in 7 articles $[17,18,22,25,35,46-48]$, customized devices were used in 8 articles $[19,20,32,34,38,44,45,49]$ and in 2 articles manual goniometry was used to measure the range of motion $[23,28]$.

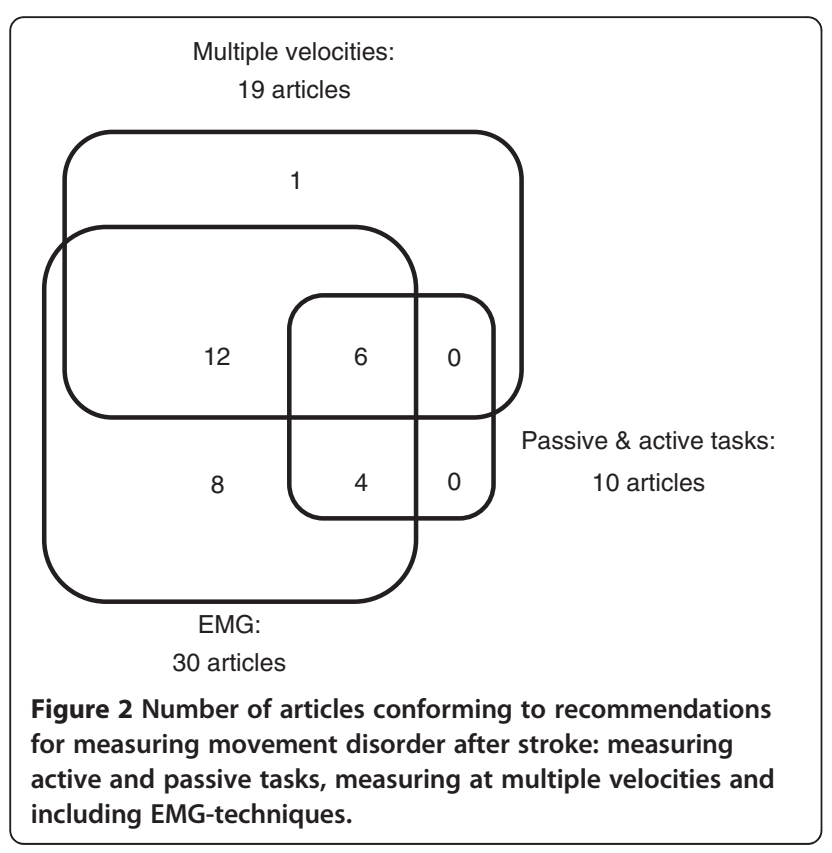

Maximum voluntary contraction was measured with a handheld dynamometer $(\mathrm{n}=1)$ [17], or a torque transducer/load cell in a (customized) device $(\mathrm{n}=11)$ [19,27-29,33,34,36,38,39,41,49]. Isometric conditions were applied in 11 articles, while in 1 article the peak active torque during flexion/extension movement was measured [19].

Stiffness or resistance to passive movement was measured as force or torque versus angle during passive movement, with the identical device as used for maximum voluntary contraction. The methods ranged from measuring peak resistance during movement $(\mathrm{n}=2)$ $[30,48]$, calculating the slope of the force-angle curve, linearized over a part $[19,20,22,23,32,43]$ or the total $[24,30,32,35,43]$ of the movement trajectory $(n=10)$, to a model fit $(\mathrm{n}=5)[33,34,38,44,45]$. A minority compared stiffness at different velocities $(n=5)[24,30,32,35,43]$.

Viscosity $(n=3)$ was derived from force and position at different velocities during passive movement $[29,31,37]$. Work $(n=2)$ was calculated as the area under the curve of moment-angle, during passive movement $[18,30]$. Mathematical models $(n=3)$ were used to compare the estimated or predicted parameter with the actual parameter. This was done once for muscle length [27], once for torque [33] and once for angle trajectory [42].

Other biomechanical parameters assessed $(n=25)$ were tracking index (correlation between target angle and actual angle) $[19,20]$, relaxation index (difference in 
angle between initial angle and first drop in pendulum test) [25], velocity dependent torque [18,33-35,44,45], phase dependent torque (timing of joint resistance compared to movement) [29,37], movement pattern (range of motion related to duration of phase) [46], miscellaneous other torque parameters $[18,23,30,38,40,50]$ and gains $[44,45]$. Most attempted to cipher some spasticity parameter, using different combinations of velocities or positions and resulting torque.

\section{Electrophysiological outcome measures}

All electrophysiological outcome measures were measured using surface electromyography (EMG). An overview of EMG outcome measures is presented in Additional file 1: Table S1.

Magnitude of EMG signal was measured during maximum voluntary contraction (isometric) $(\mathrm{n}=5)$ $[27,28,33,39,41]$, with a target force or target EMG-level $(\mathrm{n}=2)[27,39]$, during passive movement $(\mathrm{n}=18)$ [17$20,22-26,30,33,36,38,40,43,44,46]$ or during active movement [46]. Tendon taps were used in 2 articles [23,40] and H-reflex stimulation was used in 2 articles [26,36]. In all cases the EMG was rectified and/or normalized. The EMG activity during maximum voluntary contraction was mostly used as a reference value for the magnitude of reflex EMG response. In 6 cases, EMG activation was compared between different velocities or task instructions [22,30,35,39,43,46].

Threshold was described as the angle at which EMG activity started during passive movement. Thresholds were compared between different velocities of perturbation $[21,30,31,37]$. Onset was described as the latency in time between start of perturbation and start of EMG activity $[27,33,34,38,45]$.
Co-activation (or cocontraction) compared agonistic and antagonistic EMG-activity during passive movement $(\mathrm{n}=4)[19,20,44,45]$, during active movement $(\mathrm{n}=1)[46]$ or maximum voluntary contraction $(n=1)$ [34].

Other parameters of EMG $(n=9)$ that were assessed, include velocity dependent EMG signal [35], tonic threshold (extrapolation of thresholds from different velocities to zero velocity) [21], duration of activity [29], modulation of activity [29], volitional response time [27,39], slope of recruitment curve and $\mathrm{H}$-reflex related parameters [36].

\section{Pathophysiological construct of outcome measures}

Observed pathophysiological constructs were spasticity $(\mathrm{n}=16) \quad[17,21-26,32,33,35,37,44-48]$, muscle tone $[18,30,31,42,43]$, muscle overactivity $[28,39,40,50]$, paresis [49], motor control [29], impairment [19,20], coupling between extremities $[27,36,38]$, secondary changes [34] and normalization of signals [41]. Observed underlying mechanisms used to underpin the pathophysiological constructs were paresis [17,19-21,24,34,49], limited range of motion [19,20,46,50], stiffness/hypertonia [18-25,30-35,37,38,42-45,47,50], muscle overactivity/hyperreflexia $\quad[17,20-25,27-31,34-40,43,45,50] \quad$ and motor control/dexterity [19,20,29,33,46,49]. An overview of the cross-links between observed pathophysiological constructs and underlying mechanisms is presented in Table 2.

The most addressed concept was that of spasticity $(\mathrm{n}=16)$, although different definitions and interpretations were given [17,21-26,32,33,35,37,44-48]. The observed underlying mechanism was in either nonneural (stiffness, resistance) $(\mathrm{n}=4)[32,33,45,47]$, neural (muscle overactivity, hyperreflexia) $(\mathrm{n}=2)[17,46]$, or a

Table 2 Concepts and pathophysiological mechanisms categorized in articles measuring movement disorder after stroke

\begin{tabular}{|c|c|c|c|c|c|c|}
\hline \multirow[t]{2}{*}{ Concept } & \multirow[t]{2}{*}{ Articles (n) } & \multicolumn{5}{|c|}{ Pathophysiological mechanisms } \\
\hline & & Paresis & $\begin{array}{l}\text { Limited range } \\
\text { of motion }\end{array}$ & $\begin{array}{c}\text { Stiffness/ } \\
\text { hypertonia }\end{array}$ & $\begin{array}{l}\text { Muscle overactivity/ } \\
\text { hyperreflexia }\end{array}$ & $\begin{array}{l}\text { Motor control/ } \\
\text { dexterity }\end{array}$ \\
\hline Spasticity & 16 & 3 & 2 & 12 & 9 & 2 \\
\hline Muscle tone or hypertonia & 5 & 0 & 0 & 5 & 3 & 0 \\
\hline Muscle overactivity & $4^{*}$ & 0 & 1 & 1 & 4 & 0 \\
\hline \multicolumn{7}{|l|}{ Other } \\
\hline - paresis & 1 & 1 & 0 & 0 & 0 & 1 \\
\hline - motor control & 1 & 0 & 0 & 0 & 1 & 1 \\
\hline - impairment & 2 & 2 & 2 & 2 & 1 & 2 \\
\hline - coupling & $3^{\#}$ & 0 & 0 & 1 & 3 & 0 \\
\hline - secondary changes & 1 & 1 & 0 & 1 & 1 & 0 \\
\hline - normalization & 1 & 0 & 0 & 0 & 0 & 0 \\
\hline
\end{tabular}

${ }^{*}$ muscle overactivity $(n=2)$, reflex response $(n=2) ;{ }^{*}$ affected \& non affected side $(n=1)$, upper \& lower extremity $(n=1)$, proximal \& distal segment of extremity $(n=1)$. 
combination $(\mathrm{n}=8)[21-25,35,37,45]$. The remaining articles concerning the concept of spasticity did not discriminate between neural and non-neural components $(\mathrm{n}=2)[26,48]$.

The second most addressed concept was that of muscle tone $(n=5)[18,30,31,42,43]$. All five use nonneural components of muscle tone as underlying mechanism (i.e. stiffness, inertia, mechanical characteristics of passive tendomuscular and connective tissue, mechanical characteristics of activated muscle), while neural components (muscle overactivity, hyperreflexia) were separately addressed in 3 articles $[30,31,43]$.

The concept of muscle overactivity was the main topic in 4 articles $[28,39,40,50]$. Two articles distinguish between neural and non-neural properties $(n=2)[39,40]$.

The underlying mechanisms of stiffness and muscle overactivity were combined in 15 out of the 37 articles $[19,21-25,30,31,34,35,37,38,40,43,45]$.

\section{Discussion}

Since 2005, 37 articles described the use of biomechanical and/or EMG outcome measures to describe poststroke movement disorder. Nineteen of the articles strived to separate neural from non-neural components. The most frequent pathophysiological constructs were spasticity, muscle tone and muscle overactivity. Only 6 of the articles measure biomechanical and EMG outcome measures simultaneously, while applying active and passive tasks and multiple velocities.

Whilst this study limited the use of search engines to PubMed and Web of Science, it is likely that the main bulk of relevant literature is identified by using generic search terms and cross-checking references. The restriction to search only recent literature is justified by the specific aim of the study, namely, to identify current methods.

This review shows that in recent years initiatives have been taken to quantify and objectify measurements in post stroke movement disorders. It also indicates that the conceptual mainframe of separating movement disorder into neural and non-neural components was not always taken into account, i.e. active, passive and reflex contributions were not always divided. In some articles, there was a lack of consistency in administration of the underlying pathophysiological mechanism (paresis, increased stiffness and muscle overactivity) or pathophysiological concept (spasticity, muscle tone). For example: one [50] of the 4 papers on muscle overactivity did not use EMG. Another example is spasticity, which was described as velocity dependent in 13 of the 16 papers $[17,21,23-26,32,33,35,44,45,47,48]$, while only 8 of the 16 papers use multiple velocities in their tests $[21,22,24,32,33,35,37,47]$.
Measuring in different operating points is not commonplace yet, while it will allow for a more complete understanding of the capabilities of a patient with a movement disorder. Active and passive tasks instructions will give information about paresis and involuntary muscle activity, and a variation of velocities of perturbations will illuminate stiffness and reflex contributions. A more specific knowledge of the capabilities of a patient will probably lead to a more specific treatment. For example, patients with movement disorder due to severe paresis or reduced range of motion through secondary changes will not benefit from spasmolytic or neurolytic treatment. However, before treatment in spastic patients, these disorders are not systematically separated from muscle overactivity. This does not benefit the individual patient, is not cost effective and will introduce a bias in research of effect measurements after treatment.

The techniques as described in this review are mostly not available in clinical practice yet. This has led to prolonged use of clinical scores, despite their known disadvantages. We recommend that future work on movement disorder in stroke patients should be based on a clear concept and include a comprehensive and concise measurement protocol which is easily applied on and well tolerated by stroke patients. Outcome measures should be pathophysiologically meaningful and applicable in decision making for clinicians. Additionally, to increase the understanding of primary and secondary changes, longitudinal studies will be essential [51]. This will enable specialists in physical medicine and rehabilitation to tailor their therapies and, moreover, allow them to assess the effect of (experimental) interventions.

\section{Conclusion}

In the last 6 years a number of initiatives were developed to quantify and objectify movement disorder after stroke. However, the distinction between non-neural and neural components to separately assess paresis, stiffness and muscle overactivity, is not commonplace yet. A large gap has to be bridged to attain reproducible and comparable results.

Pathophysiologically clear concepts, substantiated with a comprehensive and concise measuring protocol will help professionals to identify and treat limiting factors in movement capabilities of post-stroke patients.

\section{Additional file}

Additional file 1: Table S1. Study characteristics (measured segment, number of subjects, category of research) and the biomechanical and electrophysiological outcome measures found in each article. 


\section{Abbreviations}

EMG: Electromyography; H-reflex: Hoffmann reflex, EMG response of muscle after electrical stimulation of the afferent nerve fibers; EXPLICITstroke: "EXplaining PLastICITy after stroke"; mAS: Modified Ashworth Score; ICF: The International Classification of Functioning, Disability and Health is a classification of health and health-related domains. These domains are classified from body, individual and societal perspectives by means of two lists: a list of body functions and structure, and a list of domains of activity and participation. Since an individual's functioning and disability occurs in a context, the ICF also includes a list of environmental factors [www.who.int accessed May 6th 2011].

\section{Competing interests}

The authors declare that they have no competing interests.

\section{Authors' contributions}

JMK contributed to the design of the study, carried out the literature search and wrote the manuscript. CGM is co-PI of the EXPLICIT study, contributed to the design of the present study, assisted in data interpretation and commented on the manuscript. JDG contributed to the design of the study, assisted in data interpretation and commented on the manuscript. AK contributed to the design of the study, assisted in data interpretation and commented on the manuscript. JHA is co-PI of the EXPLICIT study, contributed to the design of the study, assisted in data interpretation and commented on the manuscript. All authors read and approved of the manuscript.

\section{Acknowledgements}

EXPLICIT-stroke is funded by ZonMw grant 890000001 , Vereniging van Revalidatieartsen, Revalidatiefonds and Revalidatie Nederland.

\section{Author details}

${ }^{1}$ Department of Rehabilitation Medicine, Leiden University Medical Centre, Leiden, Netherlands. ${ }^{2}$ Faculty of Mechanical, Maritime and Materials Engineering, Delft University of Technology, Delft, Netherlands.

Received: 21 November 2011 Accepted: 22 August 2012

Published: 27 August 2012

\section{References}

1. Dietz V, Sinkjaer T: Spastic movement disorder: impaired reflex function and altered muscle mechanics. Lancet Neurol 2007, 6:725-733.

2. Meskers $C G$, Schouten $A C$, de Groot JH, de VE, van Hilten BJ, van der Helm $F C$, et al: Muscle weakness and lack of reflex gain adaptation predominate during post-stroke posture control of the wrist. J Neuroeng Rehabil 2009, 6:29.

3. Bakheit AM, Fheodoroff $K$, Molteni F: Response to Lindbergs et al'.s and Ward's commentaries. J Rehabil Med 2011, 43:815.

4. Bakheit AM, Fheodoroff K, Molteni F: Spasticity or reversible muscle hypertonia? J Rehabil Med 2011, 43:556-557

5. Lindberg PG, Maier MA, Borg J: Commentary on "Spasticity or reversible muscle hypertonia?". J Rehabil Med 2011, 43:812.

6. Pandyan AD, Gregoric M, Barnes MP, Wood D, van WF, Burridge J, et al: Spasticity: clinical perceptions, neurological realities and meaningful measurement. Disabil Rehabil 2005, 27:2-6.

7. Ward AB: Commentary on "Spasticity or Reversible Muscle Hypertonia?" J Rehabil Med 2011, 43:813-814.

8. Pandyan $A D$, Johnson $G R$, Price $\mathrm{Cl}$, Curless $\mathrm{RH}$, Barnes MP, Rodgers $\mathrm{H}$ : A review of the properties and limitations of the Ashworth and modified Ashworth Scales as measures of spasticity. Clin Rehabil 1999, 13:373-383.

9. Platz $T$, Eickhof $C$, Nuyens G, Vuadens P: Clinical scales for the assessment of spasticity, associated phenomena, and function: a systematic review of the literature. Disabil Rehabil 2005, 27:7-18.

10. Gracies JM: Pathophysiology of spastic paresis. II: Emergence of muscle overactivity. Muscle Nerve 2005, 31:552-571.

11. Gracies JM: Pathophysiology of spastic paresis. I: Paresis and soft tissue changes. Muscle Nerve 2005, 31:535-551.

12. Burridge $J H$, Wood DE, Hermens HJ, Voerman GE, Johnson GR, van WF, et al: Theoretical and methodological considerations in the measurement of spasticity. Disabil Rehabil 2005, 27:69-80.
13. Wood DE, Burridge JH, Van Wijck FM, McFadden C, Hitchcock RA, Pandyan $A D$, et al: Biomechanical approaches applied to the lower and upper limb for the measurement of spasticity: a systematic review of the literature. Disabil Rehabil 2005, 27:19-32.

14. Malhotra S, Pandyan AD, Day CR, Jones PW, Hermens H: Spasticity, an impairment that is poorly defined and poorly measured. Clin Rehabil 2009, 23:651-658.

15. Calota A, Levin MF: Tonic Stretch Reflex Threshold as a Measure of Spasticity: Implications for Clinical Practice. Topics in Stroke Rehabilitation 2009, 16:177-188.

16. Garland SJ, Gray VL, Knorr S: Muscle activation patterns and postural control following stroke. Mot Control 2009, 13:387-411.

17. Cousins E, Ward A, Roffe C, Rimington L, Pandyan A: Does low-dose botulinum toxin help the recovery of arm function when given early after stroke? A phase II randomized controlled pilot study to estimate effect size. Clin Rehabil 2010, 24:501-513.

18. Lebiedowska MK, Fisk JR: Knee resistance during passive stretch in patients with hypertonia. Journal of Neuroscience Methods 2009, 179:323-330.

19. Burridge JH, Turk R, Notley SV, Pickering RM, Simpson DM: The relationship between upper limb activity and impairment in post-stroke hemiplegia. Disability and Rehabilitation 2009, 31:109-117.

20. Turk R, Notley SV, Pickering RM, Simpson DM, Wright PA, Burridge JH: Reliability and Sensitivity of a Wrist Rig to Measure Motor Control and Spasticity in Poststroke Hemiplegia. Neurorehabilitation and Neural Repair 2008, 22:684-696.

21. Calota A, Feldman AG, Levin MF: Spasticity measurement based on tonic stretch reflex threshold in stroke using a portable device. Clin Neurophysiol 2008, 119:2329-2337.

22. Malhotra S, Cousins E, Ward A, Day C, Jones P, Roffe C, et al: An investigation into the agreement between clinical, biomechanical and neurophysiological measures of spasticity. Clin Rehabil 2008, 22:1105-1115

23. Chung SG, Van Rey E, Bai ZQ, Rymer WZ, Roth EJ, Zhang LQ: Separate quantification of reflex and nonreflex components of spastic hypertonia in chronic hemiparesis. Archives of Physical Medicine and Rehabilitation 2008, 89:700-710

24. Voerman GE, Burridge JH, Hitchcock RA, Hermens HJ: Clinometric properties of a clinical spasticity measurement tool. Disability and Rehabilitation 2007, 29:1870-1880.

25. Fleuren JF, Nederhand MJ, Hermens HJ: Influence of posture and muscle length on stretch reflex activity in poststroke patients with spasticity. Archives of Physical Medicine and Rehabilitation 2006, 87:981-988.

26. Ansari NN, Naghdi S, Hasson S, Rastgoo M: Efficacy of therapeutic ultrasound and infrared in the management of muscle spasticity. Brain Injury 2009, 23:632-638.

27. Finley JM, Perreault EJ, Dhaher YY: Stretch reflex coupling between the hip and knee: implications for impaired gait following stroke. Experimental Brain Research 2008, 188:529-540.

28. Gracies JM, Lugassy M, Weisz DJ, Vecchio M, Flanagan S, Simpson DM: Botulinum Toxin Dilution and Endplate Targeting in Spasticity: A Double-Blind Controlled Study. Archives of Physical Medicine and Rehabilitation 2009, 90:9-16.

29. Hyngstrom A, Onushko T, Chua M, Schmit BD: Abnormal Volitional Hip Torque Phasing and Hip Impairments in Gait Post Stroke. J Neurophysiol 2010, 103:1557-1568.

30. Kim DY, Park Cl, Chon JS, Ohn SH, Park TH, Bang IK: Biomechanical assessment with electromyography of post-stroke ankle plantar flexor spasticity. Yonsei Med J 2005, 46:546-554.

31. Chen JJ, Wu YN, Huang SC, Lee HM, Wang YL: The use of a portable muscle tone measurement device to measure the effects of botulinum toxin type a on elbow flexor spasticity. Arch Phys Med Rehabil 2005, $86: 1655-1660$

32. Starsky AJ, Sangani SG, McGuire JR, Logan B, Schmit BD: Reliability of biomechanical spasticity measurements at the elbow of people poststroke. Arch Phys Med Rehabil 2005, 86:1648-1654.

33. Galiana L, Fung J, Kearney R: Identification of intrinsic and reflex ankle stiffness components in stroke patients. Exp Brain Res 2005, 165:422-434

34. Kamper DG, Fischer HC, Cruz EG, Rymer WZ: Weakness is the primary contributor to finger impairment in chronic stroke. Arch Phys Med Rehabil 2006, 87:1262-1269. 
35. Pandyan AD, Van Wijck FM, Stark S, Vuadens P, Johnson GR, Barnes MP: The construct validity of a spasticity measurement device for clinical practice: an alternative to the Ashworth scales. Disabil Rehabil 2006, 28:579-585.

36. Barzi Y, Zehr EP: Rhythmic arm cycling suppresses hyperactive soleus $\mathrm{H}-$ reflex amplitude after stroke. Clin Neurophysiol 2008, 119:1443-1452.

37. Lee HM, Chen JJ, Wu YN, Wang YL, Huang SC, Piotrkiewicz M: Time course analysis of the effects of botulinum toxin type a on elbow spasticity based on biomechanic and electromyographic parameters. Arch Phys Med Rehabil 2008, 89:692-699.

38. Hoffmann G, Kamper DG, Kahn JH, Rymer WZ, Schmit BD: Modulation of stretch reflexes of the finger flexors by sensory feedback from the proximal upper limb poststroke. J Neurophysiol 2009, 102:1420-1429.

39. Black I, Nichols D, Pelliccio M, Hidler J: Quantification of reflex activity in stroke survivors during an imposed multi-joint leg extension movement. Exp Brain Res 2007, 183:271-281.

40. Chardon M, Suresh NL, Rymer WZ: A new method for reflex threshold estimation in spastic muscles. Conf Proc IEEE Eng Med Biol Soc 2009, 2009:5300-5303.

41. Hsu WL, Krishnamoorthy V, Scholz JP: An alternative test of electromyographic normalization in patients. Muscle Nerve 2006, 33:232-241.

42. Lin CC, Ju MS, Lin CW: The pendulum test for evaluating spasticity of the elbow joint. Arch Phys Med Rehabil 2003, 84:69-74.

43. Nuyens GE, De Weerdt WJ, Spaepen AJ Jr, Kiekens C, Feys HM: Reduction of spastic hypertonia during repeated passive knee movements in stroke patients. Arch Phys Med Rehabil 2002, 83:930-935.

44. Alibiglou L, Rymer WZ, Harvey RL, Mirbagheri MM: The relation between Ashworth scores and neuromechanical measurements of spasticity following stroke. J Neuroeng Rehabil 2008, 5:18.

45. Mirbagheri MM, Settle K, Harvey R, Rymer WZ: Neuromuscular abnormalities associated with spasticity of upper extremity muscles in hemiparetic stroke. J Neurophysiol 2007, 98:629-637.

46. Fleuren JF, Snoek GJ, Voerman GE, Hermens HJ: Muscle activation patterns of knee flexors and extensors during passive and active movement of the spastic lower limb in chronic stroke patients. J Electromyogr Kinesiol 2009, 19:e301-e310

47. Kumar RT, Pandyan AD, Sharma AK: Biomechanical measurement of poststroke spasticity. Age Ageing 2006, 35:371-375.

48. Bovend'Eerdt TJH, Dawes H, Sackley C, Izadi H, Wade DT: Mental techniques during manual stretching in spasticity - a pilot randomized controlled trial. Clin Rehabil 2009, 23:137-145.

49. Nef T, Quinter G, Muller R, Riener R: Effects of Arm Training with the Robotic Device ARMin I in Chronic Stroke: Three Single Cases. Neurodegener Dis 2009, 6:240-251.

50. Pohl M, Mehrholz J, Rochstroh G, Ruckriem S, Koch R: Contractures and involuntary muscle overactivity in severe brain injury. Brain Injury 2007, 21:421-432.

51. Kwakkel G, Meskers CG, van Wegen EE, Lankhorst GJ, Geurts AC, van Kuijk AA, et al: Impact of early applied upper limb stimulation: the EXPLICITstroke programme design. BMC Neurol 2008, 8:49.

doi:10.1186/1743-0003-9-61

Cite this article as: van der Krogt et al:: The gap between clinical gaze and systematic assessment of movement disorders after stroke. Journal of NeuroEngineering and Rehabilitation 2012 9:61.

\section{Submit your next manuscript to BioMed Central and take full advantage of:}

- Convenient online submission

- Thorough peer review

- No space constraints or color figure charges

- Immediate publication on acceptance

- Inclusion in PubMed, CAS, Scopus and Google Scholar

- Research which is freely available for redistribution 